DOI: http://dx.doi.org/10.12957/demetra.2014.8576

\title{
Ortorexia nervosa: adaptação cultural do orto-15
}

\section{Orthorexia nervosa: cultural adaptation of ortho-15}

Jackeline Barcelos Pontes'

Maria Inez Montagner ${ }^{2}$

Miguel Ângelo Montagner ${ }^{3}$

' Escola Técnica de Saúde de Planaltina. BrasíliaDF, Brasil.

${ }^{2}$ Programa de Pós-graduação em Saúde Coletiva. Universidade de Brasília. Brasília-DF, Brasil.

Correspondência / Correspondence Miguel Ângelo Montagner montagner@unb.br

\section{Resumo}

Introdução: $\mathrm{O}$ culto ao corpo na sociedade moderna, tomado como vetor da individualidade, coloca a beleza e a estética como fatores de felicidade e riqueza. Com os rigorosos e inatingíveis padrões estabelecidos, cresce o número de pessoas acometidas por transtornos relacionados à alimentação e a subjetividade coletiva. A ortorexia nervosa, um transtorno alimentar relativamente novo, descrito pela primeira vez em 1997, se caracteriza pela obsessão pela alimentação considerada pelo sujeito como saudável. As pessoas acometidas buscam alimentos tidos "puros", despendendo tempo e esforço na busca desta alimentação sadia que incompatibiliza a vida cotidiana e afasta das relações sociais. Objetivo: Este estudo teve como objetivo realizar a tradução e adaptação cultural do Orto-15, questionário desenvolvido em 2005 como ferramenta de percepção da ortorexia. Métodos: Tradução do Orto-15 do italiano para o português com discussão em grupo focal e aplicação de teste piloto, para que o instrumento possa ser utilizado primeiramente em estudo com alunos do curso Técnico em Nutrição de Brasília-DF, e posteriormente em outras pesquisas. Resultados: Obteve-se o Orto-15 adaptado para uso na população proposta. Conclusão: A tradução e adaptação cultural do Orto-15 possui grande importância, uma vez que no Brasil não existem estudos publicados sobre a prevalência de ortorexia. Sugerimos que novos estudos sejam realizados, a fim de determinar as propriedades psicométricas do instrumento.

Palavras-chave: Ortorexia Nervosa. Transtornos Alimentares. Comportamento Alimentar. Orto-15. 


\section{Abstract}

Introduction:The cult of body in modern society, seen as a vector of individuality, places beauty and aesthetics as happiness and wealth factors. With rigorous and unreachable established patterns, the number of people affected by food-related disorders and collective subjectivity increases. Orthorexia nervosa, a relatively recent eating disorder first described in 1997, is characterized by the obsession with what is normally seen as healthy food. Individuals affected by the disorder seek foods considered "pure", spending time and effort in the pursuit of healthy food that is incompatible with everyday life and puts them away from social relations. Objective: This study was intended to translate and culturally adapt the Ortho-15 questionnaire, developed in 2005 as a tool of perception of orthorexia. Methodology: Translation of the Ortho-15 from Italian to Portuguese followed by discussion and implementation of pilot testing with a focal group to enable the questionnaire to be firstly used in a study with Technical Nutrition students in Brasilia, Federal District, Brazil, and eventually in other studies. Results: Ortho-15 was adapted for use in the target population. Conclusion: Translation and cultural adaptation of Ortho-15 is of great importance, since there are no published studies on the prevalence of orthorexia in Brazil. Further studies to determine the psychometric properties of the questionnaire are suggested.

Key words: Orthorexia Nervosa. Eating Disorders. Eating Behavior. Ortho-15.

\section{Introdução}

O Brasil vem apresentando, assim como diversos países do mundo, um número crescente de pessoas com sobrepeso ou obesidade. Essa tendência, antes observada particularmente em países industrializados, tem sido retratada com relativa frequência em países em desenvolvimento. ${ }^{1}$

Vários fatores são apontados como responsáveis pelo aumento dos índices de obesidade na população mundial ${ }^{2}$ As mudanças sociais de médio e longo prazo, como a crescente industrialização de todas as áreas da vida humana, a partir da Revolução Industrial, aliadas a mudanças nas formas societárias e de combinação dos grupos humanos (famílias menores e monoparentais, vida urbana, alimentos transformados), levaram a uma série de mudanças nos rituais de alimentação. Dentre estas, a distância entre o domicílio e o local de trabalho, os horários escassos destinados à alimentação, o marketing constante das redes de fast food e a crescente oferta de alimentos 
industrializados são alguns fatores a influenciar os hábitos alimentares. Além disso, a diminuição da atividade física típica das sociedades modernas aumenta o impacto sobre as pessoas, gerando cada vez mais sobrepeso ou obesidade.

Como apontou Simmel, ${ }^{3}$ nossas "refeições" passaram por mudanças brutais que nos levam a dispensar pouca atenção à comensalidade e formas de partilhar o alimento. Dessa maneira, a realização das refeições entre os membros da família, a preparação dos alimentos e os rituais que situam a alimentação dentro de um contexto cultural e social próprios, nomeados por Simmel como uma "refeição", têm sido substituídos por refeições rápidas, realizadas em restaurantes, lanchonetes ou no próprio local de trabalho. Essa despersonalização do ato do comer, como se define neste trabalho, é o exato oposto do princípio do prazer na alimentação. A despersonalização significa a perda de toda ritualização da nutrição, ritualização marcada pelos valores culturais e simbólicos. De certo modo, a fuga deste padrão pode cair em seu oposto, a exatidão e precisão racionais no momento da alimentação, o que poderia levar a alguns transtornos de alimentação.

Essa modificação no modo de se alimentar, com seus reflexos no estado de nutrição do indivíduo, tem levado ao fenômeno chamado de "transição nutricional". ${ }^{4}$ A obesidade representa um sério problema de saúde pública que tende a agravar-se progressivamente. $\mathrm{O}$ aumento do peso da população pode ser apontado como um dos principais fatores de risco para inúmeras doenças. Por esse motivo, manter o corpo sem sobrepeso é amplamente incentivado por profissionais da saúde, com o intuito de melhorar a qualidade de vida da população.

Dialeticamente, o crescimento do peso das pessoas no Brasil e no mundo cresce significativamente, bem como a aversão à obesidade e às silhuetas mais cheias. Segundo Fischler, ${ }^{5}$ esta é uma das características da nossa época, o que ele nomeia como lipofobia, ou seja, uma obsessão crescente pela magreza e rejeição à obesidade. Os meios de comunicação, em particular aqueles vinculados a moda e estilo de vida, contribuem enormemente para a perpetuação de um estereótipo de magreza quase inatingível, e ao mesmo tempo almejado por muitos.

No âmbito social, a obesidade deixou de ser apenas um excesso de gordura corporal e passou a ter conotação mais ampla e indicar características negativas, que desqualificam o obeso em seu meio. ${ }^{6}$ Trata-se de um processo de estigmatização, apontado por Goffman. ${ }^{7}$ Como reflexo do mesmo fenômeno, pesquisadores constataram um uso diferenciado das tecnologias médicas, com vistas a atingir esses novos padrões estéticos ou como forma de consumo ligado a grupos ou classes sociais, por meio da realização de cirurgias plásticas cosméticas em idades cada vez mais precoces e como forma de distinção social. ${ }^{8}$

Isto tudo vem ao encontro das novas discussões em torno do objeto corpo, pois, como aponta Le Breton, "pensar o corpo é outra maneira de pensar o mundo e o vínculo social; uma perturbação introduzida na configuração do corpo é uma perturbação introduzida na coerência do mundo". ${ }^{9}$ 


\section{O corpo como expressão do social}

Nas sociedades contemporâneas, a dimensão e importância do corpo para o indivíduo são aquilatadas pelo desejo de fazer parte do mundo e ser nele reconhecido, como parte de uma sociedade e de um grupo. Podemos afirmar que o corpo é o suporte principal de nossa identidade, pois ela vai progressivamente sendo construída e amalgamada por e no nosso corpo. ${ }^{10}$

Na sociedade moderna, o corpo tem o papel de instrumento de construção da subjetividade do sujeito, nos termos de Bourdieu, do habitus individual e do grupo, ao mesmo tempo. Como núcleo determinante do sujeito, tem se tornado cada vez mais uma fonte de expressão do habitus e de mediador do pertencimento de um indivíduo na sociedade. Esse inscrito, indelével e matriz geradora de práticas, pode ser definido como "sistema de disposições socialmente constituídas que, enquanto estruturas estruturadas e estruturantes, constituem o princípio gerador e unificador do conjunto das práticas e das ideologias características de um grupo de agentes". ${ }^{11}$

Isso significa que o corpo é o lugar por excelência da incorporação do social, de tornar concretas as diferenças sociais na forma de posturas e disposições físicas. Por outro lado, o corpo representa um capital físico do qual dispõe o indivíduo na sua luta concorrencial em um campo social minado e estratificado. A beleza física, a capacidade ou habilidade valorizada socialmente (como no esporte ou nas artes) valem como um capital físico que pode significar a distinção social e a possibilidade de ascensão ou manutenção do status. Esse capital também pode ser convertido em dinheiro e poder econômico.

Tudo somado, o corpo torna-se cada vez mais central nas sociedades modernas e pós-modernas. Essa compreensão, pelos sujeitos sociais, tem acontecido cada vez mais como um valor cultural introjetado, um pouco inconsciente, que funciona de forma quase irrefletida, mas prática, no cotidiano da vida comum. As pessoas têm percebido que esse conjunto de valores culturais e simbólicos tem se alterado, mas de forma sub-reptícia, apesar de todo o alarde feito pela mídia sobre o corpo ideal. Para muitos, o que se coloca em jogo é o corpo somente, e não toda a gama simbólica de valores da sociedade.

No entanto, esses valores são estruturais, objetivos, fazem parte do poder que alguns dispositivos possuem de impor representações aos indivíduos. Para Bourdieu, "o poder simbólico, poder subordinado, é uma forma transformada, quer dizer, irreconhecível, transfigurada e legitimada, das outras formas de poder: [...] e transformando-as assim em poder simbólico, capaz de produzir efeitos reais sem dispêndio aparente de energia”. ${ }^{12}$ Esse poder simbólico exerce uma violência simbólica sobre a opinião do sujeito sobre seu corpo, sobre o modo como o indivíduo se relaciona com ele.

Partimos do pressuposto de que essa violência simbólica sobre o corpo tem gerado as chamadas "patologias culturais" com relação ao corpo, como a vigorexia, a anorexia, a bulimia, a ortorexia 
e outras patologias psicossomáticas sérias. A vigorexia pode ser tomada como resultado de uma instrumentalização do próprio corpo, que passa a ser visto pelo sujeito como aquém de suas possibilidades e de seus limites, o que dá ao indivíduo a sensação de fraqueza e de baixo rendimento; isto o remete a transgredir sempre os limites corporais e não aceitar os sinais de desequilíbrio de seu próprio organismo. A anorexia e a bulimia, duas primas ligadas à alimentação, estão diretamente relacionadas à autoimagem; e por fim, a ortorexia, ligada à relação perfeita com o alimento, alimentação assumida como um desafio e um objeto de vigilância; um modo de sobrepujar o próprio instinto alimentar.

Todas têm uma raiz compulsiva, ou seja, relacionam-se com os transtornos mentais denominados compulsivos. Mas o que não se tem discutido são justamente suas raízes de constrição social, de obrigação, de exigência da sociedade, de violência simbólica exercida pela sociedade sobre o indivíduo.

Em resposta ao culto excessivo da magreza em si e às qualidades atribuídas aos indivíduos magros, tem ocorrido a elevação do número de transtornos dismórficos relacionados à alimentação. Se a construção social dos corpos magros tem atingido a socialização primária, pode-se argumentar com segurança que a magreza tem sido incorporada ao habitus dos agentes sociais com grande força e de forma cada vez mais precoce.

Assim, a supervalorização da magreza em detrimento da saúde pode gerar uma quebra na relação harmônica do homem com o alimento. Uma consequência da "lipofobia" é a divulgação maciça, pelos meios de comunicação, de informações sobre alimentação saudável e sobre riscos à saúde que certos alimentos representam. Como consequência da busca constante pela alimentação saudável como forma de prevenção de doenças e como forma de enquadramento em um padrão estético tido como aceitável, as pessoas têm alterado seu comportamento nas refeições, optando muitas vezes pela adoção de dietas restritivas e que não se situam em seus padrões sociais, culturais e até mesmo de suas preferências.

Assim, nosso objeto são as patologias sociais, encaradas por nós como expressão do habitus dos sujeitos e da relação de gênero. Traduzindo em termos de conceitos, queremos relacionar os transtornos dismórficos corporais e suas hexis, como resultado da forma como o corpo foi docilizado e medicalizado pela sociedade moderna.

\section{Ortorexia nervosa}

Nesse contexto, novos transtornos têm sido descobertos e descritos a cada dia. Nesse campo recente, a ortorexia nervosa, um comportamento alimentar, tem sido retratada como uma desordem alimentar relativamente nova, ainda não reconhecida como transtorno pelo Diagnostic 
and Statistical Manual of Mental Disorders - IV (DSM IV). ${ }^{13}$ Ela foi descrita pela primeira vez por Bratman, em 1997, que cunhou o termo "ortorexia", que significa "alimentação correta" e vem do vocábulo latino orto (reto, direito). ${ }^{14}$

Bratman \& Knight, em seu livro Health Food Junkies, descreveram as características das pessoas com ortorexia. ${ }^{15}$ Por serem profundos conhecedores de práticas alimentares alternativas e por conviverem com pessoas adeptas do vegetarianismo e macrobiótica há muito tempo, Bratman e Knight identificaram alguns casos de ortorexia em pessoas desses grupos. Como especialistas, perceberam pessoas que por motivos médicos (alergias e intolerâncias alimentares, por exemplo) necessitaram fazer restrições dietéticas de determinado alimento ou grupo alimentar, mas que evoluíram (sem indicação clínica) para restrições alimentares bastante amplas, caracterizando um comportamento alimentar idiossincrático, depois nomeado como ortorexia. Na obra também foi proposto um primeiro questionário, composto de dez questões, para um autodiagnóstico indicador da ortorexia.

Por ser um assunto ainda pouco estudado, o número de trabalhos publicados sobre ortorexia ainda é muito restrito. Os estudos concordam que as pessoas que a apresentam têm traços de personalidade obsessiva compulsiva, sendo a ortorexia caracterizada pela obsessão patológica pela alimentação saudável, que pode levar a importantes restrições alimentares. ${ }^{16-20 .}$

Além de restrições alimentares, a disfunção leva a um comportamento típico que acaba por demandar muito tempo do sujeito na busca, seleção, preparação e adequação dos alimentos. Diferentemente da anorexia ou bulimia, a ortorexia não é uma é uma desordem alimentar quantitativa, e sim qualitativa, ou seja, as pessoas com ortorexia preocupam-se, sobretudo, com a qualidade do alimento escolhido ${ }^{16}$. Dessa forma, são excluídos da alimentação alimentos que não sejam orgânicos ou que possam passar por processamentos que ocasionem perda de nutrientes e/ ou incorporação de substâncias nocivas à saúde..$^{21}$

Além da questão da qualidade, Bratman já havia percebido e apontado que as pessoas com ortorexia tendem a se privar do convívio social, preferindo realizar suas refeições sozinhas, como forma de evitar questionamentos quanto a suas escolhas alimentares e preocupações ${ }^{14}$. Assim, o foco principal não é a perda de peso, mas sim a obtenção de uma alimentação tida como perfeita pelo sujeito. ${ }^{22}$

Os estudos realizados até então apontam que algumas categorias profissionais encontram-se mais vulneráveis para o surgimento da ortorexia. ${ }^{23-25}$. Dessa forma, estudantes e profissionais da área da saúde, que possuem nutrição nos seus currículos escolares, possuiriam maiores chances de desenvolver ortorexia. ${ }^{26}$ As desordens alimentares e alterações na imagem corporal parecem 
ser mais frequentes em pessoas cuja profissão de uma forma ou de outra exija maior cuidado com a alimentação. ${ }^{27,28}$ Quando reunidos em grupos, os indivíduos tendem a ter práticas e tomadas de decisões semelhantes.

A ortorexia pode não ser percebida, pois a busca pela alimentação saudável é incentivada e tida como um hábito que promove bem-estar e longevidade, isto é, a ortorexia parece seguir os padrões de saúde e demora a se tornar um "problema". Pessoas com ortorexia têm orgulho de seus comportamentos e escolhas, e vão progressivamente se aperfeiçoando na obtenção de alimentos tidos como puros ou superiores. Esse caráter positivo dificulta a aceitação de que comportamentos "saudáveis" podem levar ao prejuízo da saúde.

Em 2004, Lorenzo Donini e colaboradores publicaram o primeiro estudo sobre a prevalência de ortorexia em grupos populacionais. A pesquisa foi realizada em Roma, na Itália, com um grupo de 404 sujeitos. Nesse estudo foi desenvolvido e validado um instrumento para a detecção da ortorexia, nomeado Orto-15. ${ }^{16} \mathrm{O}$ questionário, composto por quinze perguntas, foi desenvolvido tendo por base o teste de dez questões propostas por Bratman. ${ }^{14}$

No Brasil não existem dados sobre a prevalência de ortorexia, o que demonstra a importância da tradução do Orto-15 para a língua portuguesa e de sua adaptação cultural, a fim de preservar o sentido original das questões que compõem o questionário. No segundo momento, já aplicamos o questionário adaptado a uma população específica, e os resultados serão publicados brevemente.

\section{Objetivo}

Realizar a tradução e adaptação cultural do Orto-15, desenvolvido por Donini e colaboradores, para posterior uso como instrumento de análise da ortorexia ao nível populacional, inicialmente na população de estudantes do curso Técnico e Nutrição e Dietética do Distrito Federal, pesquisa que será publicada posteriormente.

\section{Metodologia}

O Orto-15 foi desenvolvido em língua italiana e publicado em língua inglesa por Donini e colaboradores em 2004. ${ }^{16}$ No quadro 1, abaixo, encontra-se a versão original do questionário, em italiano, composto de 15 questões com uma escala de quatro respostas gradativas. 
Quadro 1. Questionário ORTO-15 em italiano, Donini et al. ${ }^{16}$

\begin{tabular}{|c|c|c|c|c|}
\hline & Sempre & Spesso & Talvolta & Mai \\
\hline $\begin{array}{l}\text { 1. Quando mangia fa attenzione alle calorie } \\
\text { degli alimenti? }\end{array}$ & & & & \\
\hline $\begin{array}{l}\text { 2. Quando entra in un negozio di prodotti } \\
\text { alimentari, è confuso? }\end{array}$ & & & & \\
\hline $\begin{array}{l}\text { 3. Negli ultimi } 3 \text { mesi, il pensiero del cibo è } \\
\text { stato per lei una preoccupazione? }\end{array}$ & & & & \\
\hline $\begin{array}{l}\text { 4. Le sue scelte alimentari sono condizionate } \\
\text { dalla preoccupazione per il suo stato di } \\
\text { salute? }\end{array}$ & & & & \\
\hline $\begin{array}{l}\text { 5. Il sapore è la più importante delle qualità } \\
\text { di cui lei tiene conto nel giudicare un cibo? }\end{array}$ & & & & \\
\hline $\begin{array}{l}\text { 6. È disposto a spendere di più per avere un } \\
\text { cibo sano? }\end{array}$ & & & & \\
\hline $\begin{array}{l}\text { 7. Il pensiero del cibo sano la preoccupa per } \\
\text { più di tre ore al giorno? }\end{array}$ & & & & \\
\hline $\begin{array}{l}\text { 8. Si concede qualche trasgressione } \\
\text { alimentare? }\end{array}$ & & & & \\
\hline $\begin{array}{l}\text { 9. Ritiene che il tono dell'umore incida sul } \\
\text { suo comportamento alimentare? }\end{array}$ & & & & \\
\hline $\begin{array}{l}\text { 10. Ritiene che la convinzione di alimentarsi } \\
\text { con cibi sani aumenti la sua autostima? }\end{array}$ & & & & \\
\hline $\begin{array}{l}\text { 11. Ritiene che il consumo di cibi sani } \\
\text { modifichi il suo stile di vita (frequenza } \\
\text { ristorante, amici...)? }\end{array}$ & & & & \\
\hline $\begin{array}{l}\text { 12. Ritiene che consumare cibi sani possa } \\
\text { migliorare il suo aspetto fisico? }\end{array}$ & & & & \\
\hline 13. Si sente in colpa quando trasgredisce? & & & & \\
\hline $\begin{array}{l}\text { 14. Ritiene che in commercio siano presenti } \\
\text { anche cibi non sani? }\end{array}$ & & & & \\
\hline $\begin{array}{l}\text { 15. Attualmente quando consuma i pasti, lo } \\
\text { fa da solo? }\end{array}$ & & & & \\
\hline
\end{tabular}


No instrumento foram atribuídos pesos para esta escala, sendo que ao comportamento relacionado à ortorexia foi atribuído peso 1 e ao comportamento mais saudável foi atribuído peso 4, conforme o quadro 2, a seguir.

Quadro 2. Pontuação atribuída por Donini et al. ${ }^{16}$ às questões do Orto-15.

\begin{tabular}{|l|c|c|c|c|}
\hline \multicolumn{5}{|c|}{ Escala de respostas } \\
\hline $\begin{array}{c}\text { Questões } \\
\text { agrupadas por tipo }\end{array}$ & Sempre & Muitas vezes & Algumas vezes & Nunca \\
\hline $\mathrm{n}^{\circ} 2,5,8,9$ & 4 ptos & 3 ptos & 2 ptos & 1 pto \\
\hline $\begin{array}{l}\mathrm{n}^{\circ} 3,4,6,7,10,11, \\
12,14,15\end{array}$ & 1 ptos & 2 ptos & 3 ptos & 4 ptos \\
\hline $\mathrm{n}^{\circ} 1,13$ & 2 ptos & 4 ptos & 3 ptos & 1 pto \\
\hline
\end{tabular}

Donini avaliou a capacidade preditiva para o diagnóstico da ortorexia por meio do cálculo da eficácia, sensibilidade, especificidade, valor preditivo positivo e negativo. Utilizou como limiar a pontuação <35, e nesse limiar o Orto-15 apresenta alta especificidade para o diagnóstico de ortorexia. No ponto de corte $<40$, o teste apresenta uma sensibilidade de $100 \%$ e especificidade de $73,6 \%$. O autor sugere o ponto de corte $<40$ para estudos populacionais. Esse foi o corte adotado em nosso estudo, em fase de redação e publicação.

A tradução e validação do Orto-15 são parte inicial e fundamental do estudo que investiga a prevalência de ortorexia entre estudantes dos cursos Técnicos em Nutrição e Dietética, no Distrito Federal. A população de estudo é composta pelos estudantes em diversas escolas do Distrito Federal, cujos resultados serão apresentados em outro artigo.

A tradução do instrumento foi realizada baseada na metodologia indicada pela Organização Mundial da Saúde (OMS), utilizada na tradução da versão em português dos instrumentos de avaliação de qualidade de vida (WHOQOL, 1998), ${ }^{29}$ e consiste nas etapas seguintes:

\section{a) Contato direto com o autor}

Foi realizado contato com os autores e explicados os motivos da pesquisa; eles nos disponibilizaram a versão do questionário desenvolvida originalmente em língua italiana e posteriormente traduzida (mas não adaptada) para o inglês. 


\section{b) Tradução}

O profissional responsável foi um tradutor juramentado, que realizou a tradução do texto na língua italiana para o português.

\section{c) Revisão da tradução}

Após a tradução, o texto em língua portuguesa foi objeto de um grupo focal, composto por dois estudantes do curso técnico em Nutrição e Dietética, dois representantes da população em geral, um linguista, um nutricionista, um seguidor do vegetarianismo, um psicólogo e um sociólogo, que foi o mediador do debate. As discussões foram gravadas em áudio digital e também foram tomadas notas manuscritas.

O instrumento traduzido foi debatido ponto a ponto, tanto em seu conteúdo como em sua forma em português. Muitas questões foram alteradas e o teor da mensagem adequado ao sentido mais próximo possível à cultura brasileira Pontos específicos foram melhorados e outros eliminados em parte, sem perda da questão de origem. Procurou-se a exatidão e a fidedignidade conceitual dos conteúdos. A versão final foi resultado do consenso do grupo.

\section{d) Teste piloto}

O Orto-15, traduzido e adaptado, foi aplicado em um grupo de 20 participantes, alunos dos cursos Técnico em Nutrição e Dietética e Técnico em Secretariado de uma escola profissionalizante do Distrito Federal. Optou-se por incluir os alunos do curso Técnico em Secretariado por constituírem um grupo de alunos com características semelhantes (predominância do sexo feminino, mesma forma de ingresso na instituição, mesmas regiões de origem), e que ao mesmo tempo não representavam estudantes da área da saúde. Após o preenchimento dos questionários, os alunos expuseram suas dúvidas e apontaram as questões em que tiveram maior ou menor dificuldade de compreensão. As sugestões e dificuldades encontradas foram registradas pelos pesquisadores e encaminhadas para discussão junto ao mesmo grupo focal que realizou a adaptação cultural, para homologação da versão final.

\section{Retrotradução}

Após revisão e consolidação pelo grupo focal de expertos, a retrotradução do Orto-15 foi realizada por um novo tradutor juramentado, que não participou da tradução italiano-português. 


\section{Reavaliação da retrotradução}

O questionário retraduzido foi enviado ao seu autor em sua língua original (italiano) para que ele pudesse avaliar se as questões mantinham as mesmas propriedades do questionário original e atendiam aos objetivos originalmente propostos.

Após a aprovação do autor do instrumento, o instrumento foi considerado apto a ser aplicado na população de estudantes dos cursos Técnico e Nutrição e Dietética do Distrito Federal.

\section{Aspectos éticos da pesquisa}

O estudo foi submetido à avaliação do Comitê de Ética em Pesquisa do Instituto de Ciências Humanas (CEP-IH), da Universidade de Brasília (UnB), tendo sido aprovado sob número FR 331326, em 18 de maio de 2010. Todos os estudantes que participaram foram esclarecidos sobre os objetivos e benefícios da pesquisa e concordaram em assinar o Termo de Consentimento Livre e Esclarecido (TCLE).

\section{Resultados e Discussão}

No processo de avaliação da tradução e adaptação cultural do instrumento, os sujeitos participantes do grupo focal foram selecionados de forma a garantir que as questões relacionadas tanto ao objeto de estudo (ortorexia) quanto à língua e cultura estivessem bem representadas. Bratman $^{12}$ descreve em seu livro pessoas que optaram por uma alimentação vegetariana e que possuíam alergias alimentares pareciam estar mais propensas a desenvolver ortorexia. Dessa forma, julgamos que seria importante possuir no grupo focal um participante que fosse vegetariano.

Também foram incluídos no grupo experto um psicólogo, um sociólogo e um linguista, para garantir que após a tradução, as questões resgatassem, para a população brasileira, o mesmo tipo de resposta que as questões do questionário original em italiano. O restante do grupo era constituído por um nutricionista, alunos do curso Técnico em Nutrição e Dietética e representantes da população em geral.

O Orto-15 traduzido e adaptado para a língua portuguesa encontra-se no quadro 3, abaixo: 
Quadro 3. Orto-15 adaptado por Pontes e Montagner, Brasília-DF, 2010.

\begin{tabular}{|c|c|c|c|c|}
\hline $\begin{array}{l}\text { Marcar com um } X \text { a alternativa } \\
\text { que melhor corresponde ao seu } \\
\text { comportamento em relação à comida }\end{array}$ & Sempre & $\begin{array}{c}\text { Muitas } \\
\text { vezes }\end{array}$ & $\begin{array}{l}\text { Algumas } \\
\text { vezes }\end{array}$ & Nunca \\
\hline $\begin{array}{l}\text { 1. Você fica atento(a) às calorias dos } \\
\text { alimentos quando come? }\end{array}$ & & & & \\
\hline $\begin{array}{l}\text { 2. Quando você vai a um mercado de } \\
\text { alimentos, se sente confuso a respeito do } \\
\text { que deve comprar? }\end{array}$ & & & & \\
\hline $\begin{array}{l}\text { 3. Nos últimos três meses, pensar sobre sua } \\
\text { alimentação tem sido uma preocupação? }\end{array}$ & & & & \\
\hline $\begin{array}{l}\text { 4. As suas escolhas alimentares são } \\
\text { determinadas pela preocupação com seu } \\
\text { estado de saúde? }\end{array}$ & & & & \\
\hline $\begin{array}{l}\text { 5. O sabor é a qualidade mais importante } \\
\text { que você leva em consideração ao escolher } \\
\text { um alimento? }\end{array}$ & & & & \\
\hline $\begin{array}{l}\text { 6. Normalmente, você se dispõe a pagar } \\
\text { mais por alimentos saudáveis? }\end{array}$ & & & & \\
\hline $\begin{array}{l}\text { 7. A preocupação com alimentação saudável } \\
\text { toma mais de três horas do seu dia? }\end{array}$ & & & & \\
\hline $\begin{array}{l}\text { 8. Você se permite alguma quebra da sua } \\
\text { rotina alimentar? }\end{array}$ & & & & \\
\hline $\begin{array}{l}\text { 9. Para você, o seu humor influencia o seu } \\
\text { comportamento alimentar? }\end{array}$ & & & & \\
\hline $\begin{array}{l}\text { 10. Você acredita que a convicção de se } \\
\text { alimentar saudavelmente aumenta sua } \\
\text { autoestima? }\end{array}$ & & & & \\
\hline $\begin{array}{l}\text { 11. Você acha que o consumo de alimentos } \\
\text { saudáveis modifica seu estilo de vida (ida } \\
\text { a restaurantes, amigos...)? }\end{array}$ & & & & \\
\hline
\end{tabular}




\begin{tabular}{|l|l|l|l|l|}
\hline $\begin{array}{l}\text { 12. Você acredita que consumir alimentos } \\
\text { saudáveis pode melhorar o seu aspecto } \\
\text { físico? }\end{array}$ & & & & \\
\hline $\begin{array}{l}\text { 13. Sente-se culpado(a) quando sai da sua } \\
\text { rotina alimentar? }\end{array}$ & & & & \\
\hline $\begin{array}{l}\text { 14. Você pensa que no mercado existem } \\
\text { alimentos não saudáveis? }\end{array}$ & & & & \\
\hline $\begin{array}{l}15 . \text { Ultimamente, você costuma estar } \\
\text { sozinho(a) quando se alimenta? }\end{array}$ & & & & \\
\hline
\end{tabular}

Na análise das questões que compõem o Orto-15 cabem algumas considerações, em especial no que diz respeito às questões 6,14 e 15.

A questão 6, "Normalmente, você se dispõe a pagar mais por alimentos saudáveis?", parece sofrer influência da condição socioeconômica do indivíduo. Dessa forma, uma pessoa pode não estar disposta a pagar mais por determinado alimento, não apenas porque não considera isso importante, mas porque não possui recurso financeiro para comprar determinados alimentos. No Brasil, alimentos com menores teores de gordura e açúcar, bem como alimentos cultivados sem o uso de agrotóxicos, possuem um custo consideravelmente maior. A despeito disso, a pergunta remete a um desejo, e talvez não de fato a uma possibilidade concreta.

A questão 14, "Você pensa que no mercado existem alimentos não saudáveis?", talvez resgate um pensamento que atualmente faça parte do senso comum. Se por um lado os meios de comunicação divulgam uma infinidade de campanhas de marketing de alimentos tidos por "não saudáveis", por outro, reportagens e entrevistas que discorrem sobre os perigos do consumo excessivo de certos alimentos também se tornam cada vez mais frequentes. Dessa forma, as pessoas podem estar mais atentas às questões relacionadas às propriedades nutricionais dos alimentos, o que faz com que ao entrarem em um mercado façam associações entre determinados produtos e prejuízos à saúde.

Outra consideração a ser feita refere-se à questão 15: "Ultimamente, você costuma estar sozinho(a) quando se alimenta?”. A mudança no estilo de vida, a distância entre trabalho/escola e casa, a dificuldade de transporte público e a maior inserção da mulher no mercado de trabalho são fatores que podem contribuir para que um indivíduo possa estar sozinho ao realizar suas refeições. Sabe-se que indivíduos que possuem ortorexia costumam se alimentar sem a companhia de outras pessoas, como forma de ocultar suas restrições quanto à alimentação ou para que elas não sejam percebidas. No entanto, não somente a ortorexia leva a esse caminho, mas os fatores citados acima também podem levar uma pessoa a se alimentar sozinha. 


\section{Conclusão}

Ainda muito pouco se conhece sobre a ortorexia nervosa. Questiona-se até mesmo se a ortorexia seria um novo transtorno alimentar ou apenas uma nova face da personalidade obsessiva compulsiva. Há muito a ser esclarecido sobre seus determinantes e correlação com variáreis sociodemográficas e relacionadas à saúde.

Os poucos estudos realizados divergem quanto à relação entre ortorexia e diversos variáveis, tais como: gênero, idade, nível educacional e índice de massa corporal. Como a ortorexia pode trazer graves consequências à saúde, quando comportamentos muito restritivos são adotados, torna-se de grande importância a realização de estudos que possam elucidar tais questões.

O tratamento da ortorexia deverá ser realizado por equipe multiprofissional, devendo contemplar os diversos aspectos que envolvem a ortorexia nervosa. É imprescindível o acompanhamento psicológico, de sanitaristas, psiquiátrico, sociológico, clínico e nutricional. Como a ortorexia ainda é pouco conhecida, torna-se importante que os profissionais de saúde permaneçam atentos a comportamentos indicativos deste transtorno. Caso isso não ocorra, as restrições na alimentação podem ser vistas apenas como adesão a uma alimentação saudável e os comportamentos condizentes com ortorexia podem ser incentivados.

Poucos estudos foram realizados, e não dispomos de qualquer dado publicado sobre a prevalência de ortorexia no Brasil ou América Latina. Isso torna de extrema importância a realização de pesquisas que apontem sua prevalência na população geral e em grupos considerados de risco (estudantes da área de saúde, pessoas com restrições alimentares ocasionadas por tratamento ou estilo de vida, profissionais que necessitam manter um peso considerado mais baixo).

A tradução e adaptação cultural do Orto-15 foi um passo inicial e fundamental para que seja investigada a magnitude da ortorexia no Brasil e suas relações. Torna-se de grande importância a realização de estudos para determinar as propriedades psicométricas do Orto-15, e esperamos ter contribuído com a adaptação desse instrumento.

\section{Referências}

1. Batista Filho M, Rissin A. A transição nutricional no Brasil: tendências regionais e temporais. Cad. Saúde Pública 2003; 19(1):181-91.

2. Pinheiro ARO, Freitas SFT, Corso ACT. Uma abordagem epidemiológica da obesidade. Rev. Nutr. 2004; 17(4):523-33.

3. Simmel G. Sociologia da refeição. Estudos Históricos 2004; 1(33):159-66. 
4. Monteiro CA, Mondini L, Souza ALM, Popkin BM. The Nutrition Transition in Brazil. Eur. J. Clin. Nutr. 1995; 49:105-113.

5. Fischler C. Obeso benigno obeso maligno. In: Sant'Ana DB, organizadora. Políticas do corpo. $2^{\mathrm{a}}$ ed. São Paulo: Estação Liberdade; 2005.

6. Mattos RS; Luz MT. Sobrevivendo ao estigma da gordura: um estudo socioantropológico sobre obesidade. Physis 2009; 19(2):489-507.

7. Goffman E. Manicômios, prisões e conventos. $7^{\text {a }}$ ed. São Paulo: Perspectiva; 2001.

8. Leal VCLV, Catrib AMF, Amorim RF, Montagner MA. O corpo, a cirurgia estética e a saúde coletiva: um estudo de caso. Ciênc. Saúde Coletiva 2010; 15(1):77-86.

9. Le Breton D. A Síndrome de Frankenstein. In: Sant'Ana DB, organizadora. Políticas do corpo. $2^{\mathrm{a}}$ ed. São Paulo: Estação Liberdade; 2005.

10. Montagner MA. Pierre Bourdieu, o corpo e a saúde: algumas possibilidades teóricas. Ciênc. Saúde Coletiva 2006; 11(2):515-526.

11. Bourdieu P. A economia das trocas simbólicas. São Paulo: Perspectiva; 1998.

12. Bourdieu P. O poder simbólico. Rio de Janeiro: Difel; 1989.

13. American Psychiatric Association. Diagnostic and statistical manual of mental disorders.4th ed. Washington D.C.: APA; 1994.

14. Bratman S. Original essay on orthorexia [Internet]. 1997. [acesso em 02 nov. 2009]. Disponível em: http://www.orthorexia.com/index.php?page=essay.

15. Bratman S, Knight D. Health food junkies. New York: Broadway Books; 2000.

16. Donini LM, Marsili D, Graziani MP, Imbriale M, Cannella C. Orthorexia nervosa: a preliminary study with a proposal for diagnosis and an attempt to measure the dimension of the phenomenon. Eat Weight Disord. 2004; 9(2):151-7.

17. Donini LM, Marsili D, Graziani MP, Imbriale M, Cannella C. Orthorexia nervosa: validation of a diagnosis questionnaire. Eat Weight Disord. 2005; 10(2):e28-32.

18. Sánchez RM, Moreno AM. Ortorexia y vigorexia: ¿nuevostranstornos de laconducta alimentaria? Trastornos de La Conducta Alimentaria 2007; 5(86):457-482.

19. Arusoğlu G, Kabakçi E, Köksal G, Merdol TK. Orthorexia nervosa andadaptation of ORTO-11 intoTurkish. Turk Psikiyatri Derg. 2008; 19(3):283-91.

20. Catalina Zamora ML, Bote Bonaechea B, García Sánchez F, Ríos Rial B. Orthorexia nervosa. A new eating behavior disorder? Actas Esp. Psiquiatr. 2005; 33(1): 66-8.

21. Bartrina JA. Ortorexia o laobsesión por la dieta saludable. Arch.Latinoam. Nutr. 2007; 57(4):313-5.

22. Mathieu J. What is orthorexia? J. Am. Diet Assoc. 2005; 105(10):1510-12.

23. BagciBosi AT, Çamur D, Güler C. Prevalence of orthorexia nervosa in resident medical doctors in the faculty of medicine (Ankara, Turkey). Appetite 2007; 49(3):661-6. 
24. Aksoydan E, Camci N. Prevalence of orthorexia nervosa among Turkish performance artists. Eat Weight Disord. 2009; 14(1):33-7.

25. Fidan T, Ertekin V, Issikay S, Kirpinar I. Prevalence of orthorexia among medical students in Erzurum, Turkey. Compr. Psychiatry 2010; 51(1): 49-54.

26. Kinzl JF, Hauer K, Traweger C, Kiefer I. Orthorexia nervosa in dieticians. Psychother Psychosom. 2006; 75(6):395-6.

27. Gonçalves TD, Barbosa MP, Rosa LCL, Rodrigues AM. Comportamento anoréxico e percepção corporal em universitários. J. Bras. Psiquiatr. 2008; 57(3):166-70.

28. Perini TA, Vieira RS, Vigário PS, Oliveira GL, Ornellas JS, Oliveira FP. Transtorno do comportamento alimentar em atletas de elite de nado sincronizado. Rev. Bras. Med. Esporte 2009; 15(1):54-57.

29. Fleck MPA, Coordenação. Versão em português dos instrumentos de avaliação de qualidade de vida (WHOQOL). Porto Alegre: Grupo WHOQOL; UFRGS; 1998. [acesso em: 02 nov. 2009]. Disponível em: http://www.ufrgs.br/psiquiatria/psiq/whoqol.html

Recebido: 15/12/2013

Revisado: $04 / 3 / 2014$

Aprovado: 03/4/2014 